Clawson, B. J., and Wetherby, M. (1932): Amer. Journ. Path., 8, 283. Coates, V., ANd Coombs, C. F. (1926): Arch. Dis. Child., 1, 183.

Collins, D. H. (1937): Journ. Path. Bact., 45, 97.

Coombs, C. (1910-11): Journ. Path. Bact., 15, 489.

DAwson, M. H. (1933): Journ. Exp. Med., 5\%, 845.

Fisher, A. G. T. (1922-23): Brit. Journ. Surg., 10, 52.

Fisher, A. G. T. (1923): Brit. Med. Journ., 2, 102.

Frsher, A. G. T. (1929): "Chronic (Non-Tuberculous) Arthritis." London.

Freund, E. (1928): Wien. Arch. inn. Med., 16, 73.

HAWTHORNE, C. O. (1900): "Rheumatism, Rheumatoid Arthritis and Subcutaneous Nodules." London.

Hoffa, A., and Wollenberg, G. A. (1908): "Arthritis Deformans und sogenannter chronischer Gelenkrheumatismus." Stuttgart.

Kuinge, F., AND GrzimeK, N. (1932): Virchow's Arch., 284, 646; 286, 333 and 344.

McEwen, C. (1933-34): Amer. Heart Journ., 9, 101.

NeUmann, E. (1888): Arch. mikrosk. Anat., 18, 130.

Neumann, E. (1896): Virchow's Arch., 144, 201.

Nichols, E. H. (1910): "Arthritis Deformans." Boston.

Nichols, E. H., AND RichaRdson, F. L. (1909-10): Journ. Med. Res., 21, 149.

\title{
HEBERDEN'S NODES IN A GIRL OF FIFTEEN YEARS OF AGE
}

\author{
By J. Barnes Burt, M.D.
}

K. M. S., female, age fifteen, was admitted to the Devonshire Hospital complaining of pains in the feet, hands, shoulders and spine. There was a history of pain in the hands for two years and in the elbows for some time longer. Two years previously she had been in bed for two months for some vague spinal trouble.

Previous Diseases.-Various children's ailments not specified. Tonsillectomy had been performed the previous year.

Family History.-One aunt suffered from phthisis; no history of gout or rheumatism.

Condition on Admission.-Child was fat, well nourished, and of good colour. There was some thickening of all the joints of her fingers and Heberden's nodes on all the fingers of both hands. There was some tenderness over the dorsal vertebræ, but no sign of deficiency of movement or spondylitic changes. There was definite panniculitis over the inner side of both knees, and the 
thyroid was slightly enlarged. The circulatory, nervous and respiratory systems normal. Menstruation irregular.

An X-ray of the hands showed typical Heberden's nodes on all fingers. The metacarpal bones were somewhat broad and stunted

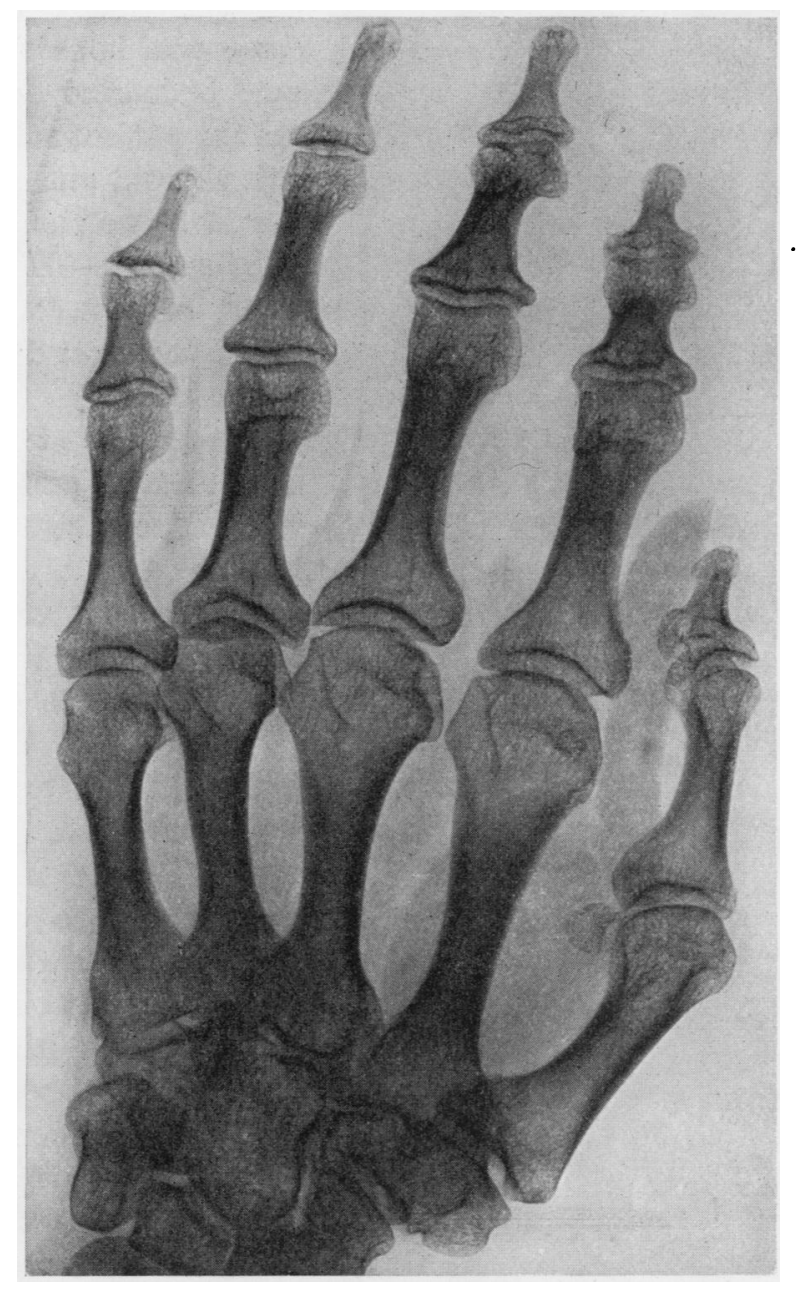

Fig. 1.-Broad and Stunted Metacarpal Bones.

and there were some bony outgrowths on all the mid-phalangeal joints (Fig. 1).

Biochemical Examination.-Sedimentation rate was normal; blood uric acid 3.3; the urine showed a faint trace of albumin; there were a few leucocytes and $B$. coli present. 
In view of the condition of the metacarpal bones an X-ray of the skull was taken and the pituitary fossa appeared to be

Right hand.
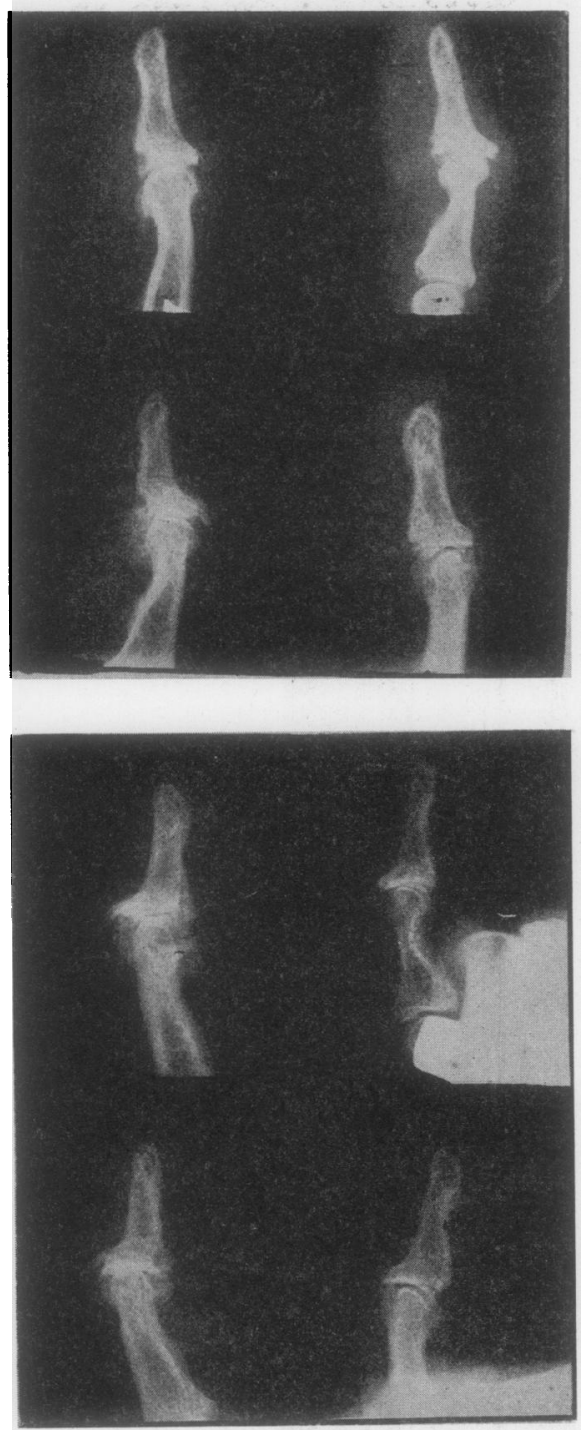

Left hand.

Fig. 2.-Heberden's Nodes. normal. The enlarged thyroid, the panniculitis and the character of the metacarpal bones suggested some endocrine deficiency, and the patient was treated with thyroid and pituitary extract as well as baths.

Discussion.-Heberden's nodes are, according to Hench, the most distinctive expression of senescent arthritis. $\mathrm{He}$ states that, very rarely, certain evidences of senescent arthritis are seen at an age as early as thirty to thirty-five. The premature form may or may not appear in conjunction with other evidence of prematurity such as menopause, greying hairs, or both. Hench also suggests tentatively that Heberden's nodes may be secondary to a vascular disturbance, an arteritis rather than arterio-sclerosis.

The writer some years ago analysed 40 consecutive cases of Heberden's nodes admitted to a Poor Law Institution, and came to the conclusion that Heberden's nodes are the result of mechanical stress and irritation of the joint margins caused by excessive use of the affected joints or weakness of the ligaments due to senescence, gout or chronic arthritis. Con- 
sidered from the mechanical point of view, these nodules serve a useful purpose; the backward pressure and in severe cases the lateral pressure is now borne by bone and is distributed over an increased surface. The notes of these cases bring out the following points:

1. Associated Conditions.-Twelve cases, or 30 per cent., had evidence of chronic gout in other parts of the body; 9 , or 22.5 per cent., had evidence of arthritis in other joints. The remaining 47.5 per cent. were all over fifty-eight years of age. These figures show clearly that Heberden's nodes are associated with some condition which leads to the weakening of the joint ligaments-either some chronic inflammatory condition such as chronic gout, or rheumatoid arthritis, or a degenerative change such as may affect all tissues in old age.

2. Occupation and Sex.-Men: 3 cases, or 7.5 per cent. Women: 37 cases, or 92.5 per cent.

Of the 3 men, 2 were joiners and 1 a bootmaker: they all suffered from chronic gout. It will be noticed that the occupations of the men necessitated special use of the last phalangeal joint.

Of the 37 women, 9 were needlewomen or dressmakers, 1 an artificial flower maker, 4 were domestic servants, 4 washerwomen, and the remaining 19 simply did housework.

The greater number of women of the lower and middle classes do needlework, and though only 9 , or 22.3 per cent., of the cases analysed actually gained their living by it, all the women in this list may be considered as needlewomen.

The large excess of women affected by Heberden's nodes over men may be explained on these lines. As previously noticed in the case of the men, the occupations of the women lead to special use of the last phalangeal joint. In no case did the nodes appear to interfere with the use of the joint, and most of the patients in this list may be considered as carrying on their occupation at the time the notes were taken.

These figures signify that occupations necessitating the special use of the last phalangeal joint predispose to the formation of Heberden's nodes.

3. Fingers Affected.-Table showing the number of times Heberden's nodes were found upon the different fingers:

\begin{tabular}{llll} 
Finger. & \multicolumn{2}{c}{ Right. } & Left. \\
Index .. & $\ldots$ & 34 cases, or 85 per cent. & 19 cases, or $47 \cdot 5$ per cent. \\
Middle. & $\ldots$ & 23 cases, or 57 per cent. & 17 cases, or $42 \cdot 5$ per cent. \\
Ring $\ldots$ & $\ldots$ & 15 cases, or 37.5 per cent. & 15 cases, or 37.5 per cent. \\
Little .. & . 13 cases, or 32.5 per cent. & 13 cases, or 32.5 per cent.
\end{tabular}


Seventy per cent. of the cases showed more than one Heberden's node. Of the 12 cases, or 30 per cent., which showed only one Heberden's node, 10 were on the right index finger only, 1 was on the left index finger only, 1 was on the right middle finger only.

In 11 cases, or 27.5 per cent., all the fingers of both hands showed Heberden's nodes. In more than half of these (6) the nodes on the right index and right middle fingers were distinctly the most prominent.

These figures show that the right index finger is the commonest position for Heberden's nodes, then comes the right middle or thimble finger; that is to say, Heberden's nodes are most often found on the fingers most used.

It is somewhat difficult to fit in the various theories as to the cause of Heberden's nodes with the case described above.

After the publication of the paper referred to above Sir Dyce Duckworth in a personal communication to the writer stated that in his experience the clergy suffered from Heberden's nodes more frequently than members of other professions. The nodes were generally situated on the right and left index fingers. This Sir Dyce Duckworth ascribed to the large amount of writing, the right index finger holding the pen and the left index finger holding down the paper.

\section{REFERENCES}

Hench, P. S.: "Acute and Chronic Arthritis," reprinted from the Nelson Loose Leaf Surgery, 1935, p. 158.

Burt, J. B.: Medical Chronicle, January, 1910, p. 223. 